\title{
SOCIAL NETWORK PRODUCTIVITY IN THE USE OF SNS
}

\author{
Rémy Magnier-Watanabe, University of Tsukuba, Tokyo \\ Michiko Yoshida, Fujitsu Research Institute, Tokyo \\ Tomoaki Watanabe, Center for Global Communications (GLOCOM), Tokyo
}

\begin{abstract}
Purpose
\end{abstract}

This study focuses on the effect of intranet-based social networking services (SNS) on the activity of the firm, in particular on the change in the number of business connections and on the time and cost-savings brought about by such SNS.

\section{Design/methodology/approach}

The authors hypothesize that the use of intranet-based SNS positively influences "social network productivity" defined as the relationship between interconnectedness and knowledge performance whereby an increase in the number of business contacts may result in a shortened and less costly retrieval of work-relevant knowledge. Drawing on a large sample of Japanese respondents, a taxonomy based on levels of organizational social capital and innovativeness was used to assess the moderating effects of social capital and innovativeness on social network productivity.

\section{Findings}

SNS were found to mildly improve efficiency in accessing knowledge or in increasing the number of business contacts. More importantly, this study reveals that in using intranet-based SNS, companies with both higher social capital and innovativeness displayed higher social network productivity.

\section{Research limitations/implications}

The use of SNS was treated implicitly and should therefore be measured independently, and detailed data on the respondents' organizations would be useful to reveal organizational clusters.

\section{Practical implications}

Because fostering social capital and innovativeness rests largely on the firm's organizational culture, leaders who want to implement SNS effectively should pay special attention to the culture of their organization.

\section{Originality/value}

In the use of business SNS, practitioners need to consider particular organizational characteristics that may affect the effectiveness of intranet-based SNS.

\section{Keywords}

Social Capital, Knowledge Management Systems, Social networks 


\section{Introduction}

In recent years, the usage of business blogs and social networking services (SNS) in Japan has steadily increased. The percentage of businesses operating those platforms in Japan increased by 2.4 percentage points in 2008 over the previous year to 6.8\%, indicating an emerging trend of utilizing "web 2.0," a generation of technologies supporting user-driven media that enable active participation, for business activities (MIC, 2008).

These platforms belong to the category of knowledge management systems (KMS), which are defined as "a class of information systems applied to managing organizational knowledge. (...) They are IT-based systems developed to support and enhance the organizational processes of knowledge creation, storage/retrieval, transfer, and application” (Alavi and Leidner, 2001, p. 114). Knowledge management includes capturing insights and experience in order to make them available to the relevant organizational members. McAfee (2006) calls this new type of collaborative platforms, such as wikis, blogs, and group-messaging software, Enterprise 2.0 technologies which can make a corporate intranet into an efficient structure. McAfee argues that "Enterprise 2.0 technologies have the potential to usher in a new era by making both practices of knowledge work and its outputs more visible” (p. 28). Among these knowledge management platforms, SNS are web-based services that allow individuals to construct a public or semi-public profile within a bounded system, articulate a list of other users with whom they share a connection, and view and traverse their list of connections and those made by others within the system (Boyd and Ellison, 2007). Social networking services "allow individuals to present themselves, articulate their social networks, and establish or maintain connections with others" and there are different types of SNS which cater to different needs (Ellison et al., 2007, p. 1143). The degree to which a user shares its profile information, and information on connections with other users, is often decided by the user within a range of options supported by the site's architecture. Some sites support features such as electronic bulletin-board system, messaging, and blog.

SNS are of special interest since they can foster knowledge creation. Davenport and Prusak (1998) argue that knowledge-creating activities take place between and within humans by means of connections and conversations. Furthermore, interconnectedness is essential in the connectionist view of knowledge which, unlike cognitivism, maintains that there can be no knowledge without a knower (Dalkir, 2005). Adopting this view, Von Krogh and Roos (1995) claim that knowledge resides both in the individuals of an organization and, at the social level, in the relations between the individuals. Intranet-based SNS, which facilitate business-related connections, can therefore be used as a supporting platform for knowledge sharing and knowledge creation activities.

This present research focuses on those SNS oriented towards work-related contexts and located on a company's intranet, thus restricted to its employees. Intranets, which are a common application of knowledge management systems, have been shown to contribute to the creation of knowledge networks (Ruggles, 1998) and to allow rapid mobilization and assimilation of knowledge assets in virtual communities (Teece et al., 1997). Such business SNS tools were introduced to enhance 
communication in the organization beyond functional and divisional boundaries, as well as to facilitate the transfer of knowledge from more experienced managers to regular employees (Minetaki and Yoshida, 2006).

This research first examines the effect of intranet-based SNS on interconnectedness and knowledge performance, and then assesses whether social capital and innovativeness influence the relationship between interconnectedness and knowledge performance. This study is quite unique in that it draws on a large empirical dataset about intranet-based SNS, which is otherwise scarce in the field.

Section two presents the theoretical foundation of this research, followed in section three by the hypotheses and the research methodology. Then, section four describes the results of the questionnaire data analysis. Section five is a discussion of the study's findings and section six concludes the research.

\section{Literature review}

This research's primary goal is to assess the effects of some cultural characteristics of organizations on the effectiveness of SNS use in improving their performance. More specifically, the authors are interested in evaluating whether social capital-rich and/or innovative organizations are better positioned to benefit from intranet-based SNS use. The effects of SNS use in this study are the increased interconnectedness among organizational members, the improved knowledge performance expressed in terms of reduced cost and time in accessing work-relevant knowledge, and the linkage between the two. The remainder of this section discusses each of these key concepts and the linkage between interconnectedness and knowledge performance will be explained in the next section.

\subsection{Knowledge performance}

Knowledge is a valuable, rare, difficult to imitate and organization-specific resource (Barney, 1991; Kogut and Zander, 1996; Spender, 1996) and previous research has shown that its creation and transfer as well as knowledge embedded in the interactions of people, tools, and tasks, provide a basis for competitive advantage in firms (Argote and Ingram, 2000). Also, the focus on resources that are developed within the organization and difficult to imitate has propelled organizational knowledge as a leading source of competitive advantage (Spender and Grant, 1996). A prevailing definition of knowledge management (KM) is the knowledge value-chain approach common to many $\mathrm{KM}$ descriptions (Shin et al., 2001). The four stages of knowledge acquisition, storage/sharing, diffusion, and application, although not necessarily sequential, are required to achieve the efficiency function of KM within the organization (Alavi and Leidner, 1999). As such, the two goals of KM are productivity gains through efficient decision-making and problem-solving, and innovation by way of bringing a new idea to market (Holsapple and Joshi, 2000).

Past research suggests that knowledge performance includes the three aspects of 1) knowledge contribution/sharing, 2) knowledge application/re-use or implementation based on knowledge contributions by others, 3) and how others have re-used or benefited from these contributions 
(Hariharan, 2002). The performance of knowledge refers to the extent whereby the deliberate management of knowledge in the organization supports the achievement of strategic business objectives. However, knowledge management should not be treated separately and instead must be integrated into the elementary processes of the organization in order to be successful (Magnier-Watanabe and Senoo, 2008).

Knowledge management is in many ways related to information technologies such as SNS. Merono-Cerdan et al. (2008) found that what they call "informational" orientation of IT use, as opposed to communicational and transactional orientations, was tied to improved corporate performance. Their study looked at discussion boards, shared databases, document repositories, and workflow support systems as major intra-firm technologies. This research's technological focus, SNS, is a tool for both communication and information exchange, but its informational aspect is of primary concern here. A particularly relevant finding is reported by Knight et al. (2005) - among the benefits of intranet usage commonly expected, the only likely benefit is faster access to information. They suggest that other benefits, including information sharing, may or may not be available depending on other factors. The current dataset advances one's understanding in that direction since this study does not focus on how much and how widely information is shared, on but how efficient it becomes for individual users to obtain knowledge from others in the organization, and how the efficiency improvement relates to organizational characteristics such as social capital and innovativeness.

In the context of new product development for instance, Ahn et al. (2006) defined knowledge performance as the capacity to create new knowledge. More generally, this performance of knowledge can be objectively assessed by examining the reduction in cost and time to access and apply the relevant knowledge which assists in the achievement of corporate objectives. One driver of knowledge performance can therefore be identified as the level of interconnectedness among the firm's members.

\subsection{Interconnectedness}

Interconnectedness has been defined as the extent to which networks tend to be cohesive or sparse (Padula, 2008). A structure is cohesive when its actors are connected with each other, whereas it tends to be sparse when actors are disconnected from each other. Interconnectedness has been cited as a crucial property for knowledge integration (Ravasi and Verona, 2001) which in turn supports the organization's competitiveness (Grant, 1996). Interconnectedness in the network also refers to an absence of structural holes (Burt, 1992) which results in a dense network, thus promoting trust among its members (Coleman, 1988; Uzzi, 1996) and social norms and sanctions that support cooperative exchanges (Coleman, 1988).

Interconnectedness is a fundamental concept of organizations. An organization is composed of a network of actors acting in coordination to achieve a specific corporate objective. Weick (1979) defines organizing as "a consensually validated grammar for reducing equivocality by means of sensible interlocked behaviors” (p. 3), whereby outcomes become the products of these interdependent actions. This definition of organization draws on the concept of bounded rationality according to which it is impossible for a single, isolated individual to reach any high degree of rationality because 
of the many alternatives to explore (Simon, 1997). A wider and richer network of individuals within or outside the company can create a mutual equivalence structure alleviating this bounded rationality since one's ability to perform consummatory acts depends on someone else performing an instrumental act (Wallace, 1961; Weick, 1979).

Indeed, as clock speed, or the speed of change in the business environment, has increased drastically (Mendelson and Pillai, 1998), information processing must gain in efficiency in order to make the right decisions. Mendelson (2000) later argues that "to successfully cope with fast clock speed, information-rich environments, organizations have to reshape their fundamental building blocks into a new architecture that [he] calls information-age architecture” (p. 513) which considers the organization as a connected ensemble of human information processors. A change in this interconnectedness can be assessed by evaluating whether the number of contacts in different groups, occupation, age, and department for instance, has increased.

\subsection{Social capital}

A typical definition of social capital is that of Putnam et al. (1993) or Putnam (1995, p. 67) which contends that "social capital refers to features of social organization such as networks, norms, and social trust that facilitate coordination and cooperation for mutual benefit.” The basis of social capital resides in the network of inter-personal and inter-organizational ties that exist in the social environment (Putnam, 2004). This social network is characterized by a set of concrete interpersonal relations that tie individuals with other individuals (Berkowitz, 1982). Tsai and Ghoshal (1998) have conducted empirical analysis on the role of social capital in the workplace and have decomposed social capital into the three parts of social interaction ties, shared vision, and trust and trustworthiness.

Social capital has been found to increase the efficiency of organizational action and support cooperative behavior, hence contributing to innovation and value creation (Coleman, 1990; Nahapiet and Ghoshal, 1998), and to positively affect the "speed and efficiency in the creation and transfer of knowledge” (Kogut and Zander, 1996). Indeed, through social interactions, actors gain access to other's resources and have more opportunities to exchange these resources (Tsai and Ghoshal, 1998). Adler and Kwon (2002) have noted for instance that social capital is critical for organizations since it "can be mobilized to facilitate collective action" (p. 17). Previous research has also shown social capital to be a moderating factor between the use of knowledge management systems and its capacity to create and transfer knowledge (Sherif et al., 2006).

\subsection{Innovativeness}

Innovativeness, or the characteristic of being innovative, denotes that a firm develops new plans or introduces new products or new services. Incidentally, social capital has been shown to be very important in determining innovativeness (Tsai and Ghoshal, 1998; Subramaniamand and Youndt, 2005).

Booz, Allen, and Hamilton (1982) for instance classify innovation strategies in terms of their newness to the market and the company. For the company, low innovativeness includes improvements 
to existing product lines or cost reductions, medium innovativeness refers to the addition of new product lines, and high innovativeness involves new to the world products (Van Trijp and Van Kleef, 2008).

Bigoness and Perreault (1981) have argued that innovation is multifaceted and may be a process, idea, concept, or product. Rogers (1962) openly recognized that innovativeness was a relative construct since diffusion rates differ among innovations, and early adopters may be considered as laggards in other social systems.

\section{Hypotheses and Sample Data}

\subsection{Hypotheses}

This research focuses on the effect of intranet-based SNS on the change in the number of business connections and on the time and cost-savings related to knowledge sharing brought about by such SNS. The first hypothesis is that SNS are perceived to have increased interconnection among members of the organization, and reduced the time and cost of knowledge sharing. One may point out that this hypothesis is rather simplistic and techno-deterministic. It is apparent that not all SNS are used effectively, and it would be more useful to identify some of the factors that influence the effectiveness of SNS use on knowledge sharing. The second hypothesis posits that the more interconnected members of an organization become, as a result of SNS usage, the more they gain in terms of time and cost-savings for knowledge sharing. This hypothesis is meant to confirm findings from previous research with the current data set. The third and main hypothesis deals with how particular organizational features shape the effect of SNS use on knowledge sharing. Namely, social capital and innovativeness are expected to positively influence social network productivity defined as the relationship between interconnectedness and knowledge performance whereby an increase in the number of business contacts may result in a shortened and less costly discovery of relevant knowledge (Figure 1).

Given the very nature of intranet-based SNS which enhance connections and understanding among organizational members, it is reasonable to expect that their use will improve an organization's interconnectedness and knowledge performance. However, some organizations are probably better positioned to benefit from SNS use than others, and the current dataset explores the moderating effects of two characteristics, specifically social capital and innovativeness. Without a doubt, moderator variables are important because specific factors are often assumed to reduce or enhance the influence that specific independent variables have on specific dependent variables (Baron and Kenny, 1986).

[Insert Figure 1 here]

This main hypothesis is formulated partly because of the limitations associated with the data set the product of surveys conducted for another research project. But there are good reasons to think that social capital and innovativeness contribute to social network productivity. In particular, organizations 
with richer social capital would take advantage of the improved interconnectedness more, because people who have a stronger sense of shared identity and trust feel less hesitant to exploit their newer relations. Similarly, if the organization is one that produces more new products, services, and plans, its members are more likely to reach out to others in seeking information and knowledge.

The relationships between social capital and knowledge performance, and between innovativeness and knowledge performance were first examined. However, the results were inconclusive and no clear pattern appeared. Because these inconsistent results can be interpreted in a number of ways, the authors decided instead to narrow their analysis down to the influence of these two variables on social network productivity which offers some more constructive findings.

\subsubsection{Social capital effects on knowledge performance}

Social capital, built on trust, can smooth the exchange of knowledge, and therefore becomes a relevant investment for firms that wish to strengthen their knowledge management capability. Past research has found for instance that social enablers such as trust and reward mechanisms are more important than technical support in isolation for facilitating knowledge sharing (Choi et al., 2008).

Intranet-based SNS can be thought of as a kind of strategic communities defined as "both emergent and strategic, as negotiated inter-organizational relationships that are associated with creative yet strategic thinking and action in an ongoing communicative and collaborative process, dependent on neither market nor hierarchical mechanisms of control” (Kodama, 2005, p. 28; Kodama, 2000). Kodama (2005) contends that these communities are based on the Japanese concept of 'ba' or shared spaces for emerging relationships that serve as a foundation for knowledge creation (Nonaka et al., 2000), and that new knowledge is continuously created in the process of merging communities to form new 'ba' based on current needs. This view of strategic communities building upon 'ba' and at the source of knowledge creation highlights the importance of both social capital and knowledge improvement respectively.

However, the causality linkage between online networks and social capital is not unidirectional since "voluntary cooperation [such as that found in intranet-based SNS] depends on social capital" (Putnam et al., 1993, p. 177). In this context, Putnam et al. (1993) showed that norms of generalized reciprocity for favors received and the network promote social trust and cooperation because they reduce incentives to defect, reduce uncertainty, and provide models for future cooperation. As a result, in testing the hypothesis that intranet-based SNS positively affect the relationship between interconnectedness and knowledge performance, the effect of the firm's social capital will be assessed as moderating variable on that relationship.

\subsubsection{Innovativeness effects on knowledge performance}

From a knowledge-based perspective, the creation and sharing of knowledge is considered to be critical for innovation (Nonaka and Takeuchi, 1995; Tsai, 2001). Firms engaging in knowledge management activities will therefore be more likely to have the ability to exploit such knowledge to invest in research activities, develop new products, processes or services and thus enhance its 
innovation outcomes and performance (Jiang and Li, 2009). The awareness and internalization of this relationship can lead to a specific type of behaviors for those firms with a high level of innovativeness. Jordan and Segelod (2006) have argued that differences in innovativeness may influence the usage of various external knowledge actors or sources.

A firm that is aware of this relationship and has internalized its benefits will therefore pay special attention to any action influencing knowledge performance such as the level of interconnectedness of its members. Hence, it is hypothesized that the firm's level of innovativeness influences the relationship between interconnectedness and knowledge performance, whereby a higher level of innovativeness results in stronger social network productivity.

\subsection{Sample and constructs}

The data was gathered by the Economic Research Center of the Fujitsu Research Institute in Tokyo and is part of a biannual on-line survey on the intra-organizational use of SNS and blogs that started in August 2006. This research uses the dataset from February 2008 which includes 1,362 respondents. Two kinds of surveys have been conducted each time, one targeting corporate managers, board members, department managers, section managers and assistant managers who let employees use job-related SNS in their Intranets (the respondents are limited to those who have a grasp of what job-related Intranet SNSs are being used for), and the other targeting employees ${ }^{1}$ who actually use job-related SNS on the Intranet. The dataset does not reveal the number of organizations respondents belong to and therefore cannot account for organizational clusters for the variables included in the survey.

Table 1: Sample demographics, industry, and occupation

\begin{tabular}{lrr|lrr}
\hline & Percentage & $\mathrm{N}$ & & Percentage & $\mathrm{N}$ \\
\hline Gender & & & Area & & \\
Male & $76.5 \%$ & 1042 & Kanto & $56.5 \%$ & 769 \\
Female & $23.5 \%$ & 320 & Non-Kanto & $43.5 \%$ & 593 \\
Age & & & Industry & & \\
20s & $22.0 \%$ & 300 & Non-manufacturing & $73.3 \%$ & 998 \\
$30 \mathrm{~s}$ & $42.9 \%$ & 584 & Manufacturing & $26.7 \%$ & 364 \\
$40 \mathrm{~s}$ & $26.7 \%$ & 363 & Occupation & & \\
$50 \mathrm{~s}$ & $7.9 \%$ & 108 & Public officer & $3.8 \%$ & 52 \\
Over 60 & $0.5 \%$ & 7 & Corporate manager / board member & $4.8 \%$ & 66 \\
Marital status & & & Employee (non-engineer) & $34.9 \%$ & 475 \\
Single & $38 \%$ & 517 & Employee (engineer) & $40.7 \%$ & 555 \\
Married & $62 \%$ & 845 & Employee (other) & $15.7 \%$ & 214 \\
\hline
\end{tabular}

The surveys draw upon a pool of potential respondents maintained by an Internet research service company, and are therefore not based on random-sampling. However, the data covers respondents from all over Japan with very diverse demographics (Table 1). The variables used to create the social networking productivity construct, interconnectedness (INT) and knowledge performance (KP), use

\footnotetext{
${ }^{1}$ Employees include both full-time and part-time employees.
} 
explicit questions on the effect of SNS in the organization and therefore indirectly assess the impact of SNS. The moderating variables, social capital (SC) and innovativeness (INN), use general questions beyond the role of SNS.

Interconnectedness (INT) includes 9 questions on the direct effect of SNS on the number of business contacts and the resulting enthusiasm and affection for the company. Knowledge performance (KP) consists of 8 questions on the direct effect of SNS on the reduction in cost and time to acquire, share, diffuse and apply knowledge in decision-making. Social capital (SC) contains 8 questions on the employees' trust and affection for the company, and the general atmosphere in the organization. Last, innovativeness (INN) is a subjective measure of new services and products launched, and plans formulated in the last three years in the company. All questions in the survey were asked using a 5-point likert scale, except for innovativeness's three items which are binary.

It is important to note that SNS are not measured as independent variables in this research, and that instead, questions assess their effect on interconnectedness and knowledge performance. This atypical research design, measuring SNS indirectly, originates from the focus on SNS users, regardless of their perceptions of SNS, and from that fact that such particular data had already been collected.

\section{Analysis}

\subsection{Factor analysis}

A factor analysis with varimax rotation confirmed the convergent validity of the four constructs (Table 2). Four components with eigenvalue above 1 were generated and revealed that in fact, the questions on interconnectedness, knowledge performance, social capital, and innovativeness could be grouped into four factors mostly consistent with the intended constructs. The only difference with the intended constructs is for the question on the improvement in mutual understanding brought about by SNS, which equally loaded on interconnectedness (factor 1 ) and knowledge performance (factor 2). In this research, this question is more relevant to interconnectedness since it measures a benefit of SNS related to a greater number of business connections. The loadings show that there were nine questions for interconnectedness (factor 1) explaining about 19\% of the total variance, seven for knowledge performance (factor 2) explaining about $16 \%$ of the total variance, eight for social capital (factor 3 ) explaining about $14 \%$ of the total variance, and three for innovativeness (factor 4) explaining about $7 \%$ of the total variance. Those four factors alone explain $58 \%$ of the total variance.

\subsection{Data validity and reliability}

The internal consistency of the constructs was assessed by examining Cronbach's alpha (Table 3) - 0.933 for interconnectedness, 0.916 for knowledge performance, 0.859 for social capital, and 0.892 for innovativeness - and suggests reliable measurement instruments (Kline, 1999). The item-to-total correlation, between each item and the sum of the remaining items, was used to assess convergent validity (Table 3). All item-to-total correlation scores were higher than 0.3 , which indicated good reliability (Field, 2005). The factor loadings of the previous factor analysis are used to measure the discriminant validity of the questionnaire items making up the four constructs (Table 2). 
Table 2: Rotated component matrix of the principal-component analysis of all four constructs

\begin{tabular}{|c|c|c|c|c|}
\hline & \multicolumn{4}{|c|}{ Component } \\
\hline & 1 & 2 & 3 & 4 \\
\hline & INT & $\mathrm{KP}$ & $\mathrm{SC}$ & INN \\
\hline Increased \# of contacts in different occupations & .790 & & & \\
\hline Increased \# of contacts in different age groups & .788 & & & \\
\hline increased \# of contacts in the same age group & .781 & & & \\
\hline Increased \# of contacts in the same occupation & .772 & & & \\
\hline Increased \# of contacts in the same department & .750 & & & \\
\hline Increased \# of contacts in different departments & .750 & & & \\
\hline Improved the enthusiasm for following dreams & .585 & & & \\
\hline Improved the affection for the company & .510 & & & \\
\hline Decreased time for collection of information & & .727 & & \\
\hline Shortened the time to find key persons & & .708 & & \\
\hline Shortened the time to acquire knowledge from key persons & & .693 & & \\
\hline Shortened the time to interpret knowledge and apply it to business & & .686 & & \\
\hline Widened employees' views & & .680 & & \\
\hline Improved the speed for decision-making & & .663 & & \\
\hline Decreased cost for collection of information & & .634 & & \\
\hline Improved understanding of other employees & .495 & .496 & & \\
\hline Employee likes company & & & .738 & \\
\hline Trust for other employees & & & .704 & \\
\hline $\begin{array}{l}\text { Enthusiastic about pursuing the goals and dreams of the whole } \\
\text { company }\end{array}$ & & & .702 & \\
\hline Open atmosphere to consult with other employees & & & .685 & \\
\hline Managers express understanding when collaborating beyond divisions & & & .597 & \\
\hline Easiness of employees' opinions to reach management & & & .570 & \\
\hline Managers support financially when collaborating beyond divisions & & & .497 & \\
\hline $\begin{array}{l}\text { Help other employees' work though not concerned with one's own } \\
\text { business }\end{array}$ & & & .486 & \\
\hline New services & & & & .777 \\
\hline New plans & & & & .756 \\
\hline New products & & & .409 & .658 \\
\hline$\%$ of Variance & 19.458 & 16.451 & 14.494 & 7.713 \\
\hline Cumulative \% & 19.458 & 35.909 & 50.403 & 58.116 \\
\hline
\end{tabular}

Extraction Method: Principal Component Analysis. Rotation Method: Varimax with Kaiser Normalization. Rotation converged in 7 iterations.

Table 3: Reliability tests for all four constructs

\begin{tabular}{lccc}
\hline Construct & $\begin{array}{c}\text { Number of } \\
\text { questions }\end{array}$ & $\begin{array}{c}\text { Reliability } \\
\text { (Cronbach’s alpha) }\end{array}$ & $\begin{array}{c}\text { Convergent validity } \\
\text { (correlation of item with total score-item) }\end{array}$ \\
\hline Interconnectedness & 9 & 0.933 & $0.786 ; 0.782 ; 0.799 ; 0.798 ; 0.794 ; 0.802 ; 0.658 ;$ \\
& & & $0.647 ; 0.688$ \\
Knowledge performance & 7 & 0.916 & $0.642 ; 0.747 ; 0.667 ; 0.711 ; 0.732 ; 0.762 ; 0.758 ;$ \\
Social capital & 8 & 0.859 & $0.677 ; 0.635 ; 0.665 ; 0.622 ; 0.660 ; 0.600 ; 0.437 ;$ \\
Innovativeness & 3 & 0.892 & 0.570 \\
\hline
\end{tabular}

\subsection{Descriptive statistics}

The mean and standard deviation of the questions on knowledge performance and interconnectedness provide a basis to assess whether the use of intranet-based SNS improve 
organizational performance.

The questions were asked in such a way that scores of 1 and 2 indicate that SNS have a negative effect on knowledge performance and interconnectedness, a score of 3 suggests that SNS have no effect, and scores of 4 and 5 imply that SNS have a positive effect. And since all the means of questions on both knowledge performance and interconnectedness items are above 3.0 (min=3.22 and min=3.13 respectively) but below 3.37 and 3.29 respectively, and that a one-sample t-test showed that these means were significantly different from $3(\mathrm{p}<0.05)$, then it can be concluded that in general, SNS are found to have a mild significant positive effect on knowledge performance and interconnectedness (Table 4). The standard deviations of the components of these two constructs were found to be relatively similar to each other, ranging from 0.646 for the question on the improvement in affection for the company to 0.772 for the item on the decrease in time for the collection of information.

Table 4: Descriptive statistics of the questions on knowledge performance and interconnectedness

\begin{tabular}{llccc}
\hline & Knowledge performance items & Valid N & Mean & S.D. \\
\hline KP1 & Decreased time for collection of information & 1362 & 3.328 & .772 \\
KP2 & Shortened the time to find key persons & 1362 & 3.337 & .747 \\
KP3 & Shortened the time to acquire knowledge from key persons & 1362 & 3.314 & .729 \\
KP4 & Shortened the time to interpret knowledge and apply it to business & 1362 & 3.294 & .722 \\
KP5 & Widened employees' views & 1362 & 3.369 & .748 \\
KP6 & Improved the speed for decision-making & 1362 & 3.224 & .689 \\
KP7 & Decreased cost for collection of information & 1362 & 3.253 & .707 \\
\hline & Interconnectedness items & Valid N & Mean & S.D. \\
\hline INT1 & Increased \# of contacts in different occupations & 1362 & 3.25 & .712 \\
INT2 & Increased \# of contacts in different age groups & 1362 & 3.26 & .716 \\
INT3 & increased \# of contacts in the same age group & 1362 & 3.22 & .688 \\
INT4 & Increased \# of contacts in the same occupation & 1362 & 3.22 & .694 \\
INT5 & Increased \# of contacts in the same department & 1362 & 3.20 & .684 \\
INT6 & Increased \# of contacts in different departments & 1362 & 3.29 & .721 \\
INT7 & Improved the enthusiasm for following dreams & 1362 & 3.14 & .677 \\
INT8 & Improved the affection for the company & 1362 & 3.13 & .646 \\
INT9 & Improved understanding of other employees & 1362 & 3.27 & .707 \\
\hline
\end{tabular}

Next, the distribution of the respondent's answers on the influence of SNS on first knowledge performance and second on interconnectedness (Figure 2). Between 7\% and 9\% of the respondents believe SNS to negatively affect knowledge performance (aggregate percentages of 1 and 2 scores range between $7.3 \%$ and $9.5 \%$ ), $30 \%$ to $40 \%$ consider SNS to positively affect knowledge performance (aggregate percentages of 4 and 5 scores range between $28.0 \%$ and $41.5 \%$ ), and $50 \%$ to $65 \%$ believe SNS to not affect knowledge performance in terms of cost, time, or perspective (aggregate percentages of 3 scores range between $50.6 \%$ and $64.7 \%$ ).

[Insert Figure 2 here]

Between $8 \%$ and $9 \%$ of the respondents believe SNS to negatively affect interconnectedness (aggregate percentages of 1 and 2 scores range between 8.1\% and 8.9\%), 20\% to 35\% consider SNS to 
positively affect interconnectedness (aggregate percentages of 4 and 5 scores range between 21.5\% and $34.8 \%$ ), and 55\% to 70\% believe SNS to not affect the number of business contacts (aggregate percentages of 3 scores range between $56.7 \%$ and $69.7 \%$ ). Based on these observations, SNS are found to improve efficiency in accessing knowledge more so than in increasing the number of business contacts and strengthening the bonds among employees.

There were no significant correlations or very low significant correlations between demographics (sex, age, marital status), function (manager or employee), location (prefecture), and industry (manufacturing or non-manufacturing), and the effect of SNS use on either knowledge performance or interconnectedness. This indicates that there is no significant bias attributable to respondents' demographics or other characteristics and that these do not need to be controlled for in subsequent analyses. Besides industry, all other characteristics above are specific to the respondents, and therefore, this absence of correlations suggests that their answers are not skewed by individual attributes.

Table 5 reveals that constructs using the same types of questions were more highly correlated, such as the relationship between interconnectedness and knowledge performance constructs using questions on the change resulting from the effect of SNS use $(\mathrm{R}=0.720, \mathrm{p}<0.001)$, and the relationship between social capital and innovativeness using general questions on their condition $(R=0.618$, $\mathrm{p}<0.001)$. The other paired correlations were found to be lower $(\mathrm{p}<0.001)$. These correlations were all found to be below 0.8, thus removing any concern of multicollinearity (Field, 2005).

Table 5: Correlations between the four constructs of knowledge performance, interconnectedness, social capital, and innovativeness

\begin{tabular}{|c|c|c|c|c|c|}
\hline & & KP & INT & SC & INN \\
\hline \multirow[t]{3}{*}{$\mathrm{KP}$} & Pearson correlation & 1.000 & $.720^{* *}$ & $.355^{* *}$ & $.324^{* *}$ \\
\hline & Significance (two-tailed) & & .000 & .000 & .000 \\
\hline & $\mathrm{N}$ & 1362 & 1362 & 1362 & 1362 \\
\hline \multirow[t]{3}{*}{ INT } & Pearson correlation & & 1.000 & $.314^{* * *}$ & $.310^{* *}$ \\
\hline & Significance (two-tailed) & & & .000 & .000 \\
\hline & $\mathrm{N}$ & & 1362 & 1362 & 1362 \\
\hline \multirow[t]{3}{*}{ SC } & Pearson correlation & & & 1.000 & $.618^{* * *}$ \\
\hline & Significance (two-tailed) & & & & .000 \\
\hline & $\mathrm{N}$ & & & 1362 & 1362 \\
\hline \multirow[t]{2}{*}{ INN } & Pearson correlation & & & & 1.000 \\
\hline & Significance (two-tailed) & & & & 1362 \\
\hline
\end{tabular}

${ }^{* *} \mathrm{p}<0.001$

\subsection{Moderated Regression}

The standard method to test moderation effects is to integrate interaction terms within a regression model. A stepwise regression analysis with three-way interactions was first performed, testing the relationship between the independent variable interconnectedness and the dependent variable knowledge performance, moderated by social capital and innovativeness. The analysis yielded two regression models, the first one with interconnectedness as sole predictor, and the second one with interconnectedness as predictor and social capital as moderator (Table 6). 
The explanatory power of these two models was evaluated based on the amount of variance in the dependent construct for which the models could account $\left(\mathrm{R}^{2}\right)$. The first model could only explain $1 \%$ of the variance for knowledge performance $(p<0.001)$, while the second one only a little more with $1.5 \%$ of the variance $(\mathrm{p}<0.001)$. Although these values were below $10 \%$, which was proposed by Falk and Miller (1992) as indication of substantive explanatory power, results show that interconnectedness moderated by social capital is still a significant predictor of knowledge performance $(\mathrm{p}<0.001)$.

Table 6: Stepwise regression analysis results with interconnectedness as independent variable, knowledge performance as dependent variable, and social capital and innovativeness as moderators

\begin{tabular}{llccccc}
\hline \multirow{2}{*}{ Model } & \multicolumn{2}{c}{ Unstandardized Coefficients } & Standardized Coefficients & & Sig. \\
& & $\mathrm{B}$ & Std. Error & $\beta$ & & \\
\hline 1 & (Constant) & $-3.368 \mathrm{E}-19$ & .027 & & .000 & 1.000 \\
& INT & .104 & .027 & .104 & 3.856 & .000 \\
\hdashline 2 & (Constant) & .000 & .027 & & -.014 & .989 \\
& INT & .091 & .027 & .091 & 3.344 & .001 \\
& INT*SC & .063 & .023 & .074 & 2.722 & .007 \\
\hline
\end{tabular}

Dependent Variable: KP

However, this moderated regression analysis does not take into account the possibility that a stronger relationship between interconnectedness and knowledge performance may exist in smaller segments of the cases. For instance, it may be useful to examine the strength of that relationship for those with high social capital and low innovativeness, or for any group with a particular combination of these two moderating variables. Taxonomy-based analysis is therefore conducted to give a closer look at the data structure and discover the effects that could be overlooked by an aggregate-level analysis.

\subsection{Taxonomy}

In order to assess the moderating effects of social capital and innovativeness on social network productivity expressed in the correlation of interconnectedness and knowledge performance, the sample was divided into nine sub-groups based on the mean of answers to social capital and innovativeness questions.

Three distinct groups were thus created, with the high group scoring one standard deviation above the mean, the low group scoring one standard deviation below the mean, and the medium group scoring in between (high $>$ mean +1 S.D. $>$ mid $>$ mean -1 S.D. $>$ low) ${ }^{2}$. It is important to note that the following taxonomy (Table 7) is not a cross-tabulation of descriptive statistics, but an account of the social network productivity (expressed as the correlation of interconnectedness and knowledge performance) for each group based on levels of social capital and innovativeness.

\footnotetext{
${ }^{2}$ This taxonomy doesn't need to consider the cases sitting on the boundaries of the sub-groups since individual answers are all integers (5-point Likert scale).
} 
Table 7: Taxonomy of cases based on levels of social capital and innovativeness

\begin{tabular}{lccccc}
\hline & Mean & S.D. & $\begin{array}{c}\text { High } \\
>\text { Mean + 1S.D. }\end{array}$ & Mean +1 1S.D. $<\mathrm{X}<$ Mean -1 1S.D. & $\mathrm{X}<$ Mean -1 S.D. \\
\hline Social capital & \multirow{3}{*}{3.32} & 0.674 & $\mathrm{X}>3.994$ & $3.994<\mathrm{X}<2.646$ & $\mathrm{X}<2.646$ \\
\% (N) & & & $18.6 \%(255)$ & $64.2 \%(880)$ & $16.6 \%(227)$ \\
Innovativeness & \multirow{3}{*}{3.08} & \multirow{2}{*}{0.838} & $\mathrm{X}>3.918$ & $3.918<\mathrm{X}<2.242$ & $\mathrm{X}<2.242$ \\
\% (N) & & & $21.1 \%(289)$ & $60.7 \%(832)$ & $17.6 \%(241)$ \\
\hline
\end{tabular}

Table 7 reveals that the distribution of the sample based on high, medium, and low social capital, as well as high, medium, and low innovativeness is quite comparable. A 3 by 3 matrix (Figure 3) shows the number of cases, distribution (\%), and social network productivity for high, medium, and low social capital groups (columns) and innovativeness groups (rows), as previously defined. These nine groups are labeled for convenience from A1 to C3 with the letter indicating the level of social capital, and the number representing the level of interconnectedness (A, 1=low; B, 2=medium; C, 3=high).

[Insert Figure 3 here]

Cases with both medium social capital and medium interconnectedness (B2) make up the bulk of the sample ( $\mathrm{N}=609$; 44.7\%) while those high in one and low in the other ( $\mathrm{A} 3, \mathrm{C} 1)$ consist of only a few cases ( $\mathrm{N}=8 ; 0.6 \%$ and $\mathrm{N}=7 ; 0.5 \%$ respectively).

Having divided respondents into nine groups based on social capital and innovativeness, the authors measured the statistical significance of the differences in social network productivity, i.e. in the correlations of interconnectedness and knowledge performance. They used Fisher's (1915) r-to-z transformation, a method of transforming product-moment correlation coefficients into standard scores or $\mathrm{z}$ scores to facilitate interpretation and to enable testing for the significance of the difference between two correlation coefficients. Table 8 reveals that social network productivity is significantly different $(\mathrm{p}<0.05$ or $\mathrm{p}<0.001)$ only between C3 and each of B1, B2, B3, and C2. In other words, the difference is statistically significant only between the group with both high social capital and high innovativeness (C3) and those with medium social capital and low innovativeness (B1), with both medium social capital and medium innovativeness (B2), with medium social capital and high innovativeness (B3), and with high social capital and medium innovativeness (C2).

Actually, the correlation between social capital and innovativeness is relatively high for the whole sample ( $R=0.618, p<0.001$, see Table 5), thus suggesting that most companies high in either one of these two characteristics are rarely low in the other, and vice versa. If this range of distributions were to represent the strategic options available to companies, then it is very unlikely that a company would be successful at improving one of these two characteristics alone without also increasing the other.

When looking at the groups among which differences in social network productivity are significant, those cases with both high social capital and high innovativeness (C3) display the 
strongest social network productivity $(\mathrm{R}=0.796, \mathrm{p}<0.001)$. Again, drawing strategic implications from this observation, and because as previously mentioned companies were found to usually exhibit similar levels of social capital and interconnectedness, this may be the most efficient position to target. However, because differences in social network productivity were found to be statistically not significant among the groups excluding C3, no conclusion can be drawn regarding which arrangement is preferable in the event cases do not belong to the high social capital and high innovativeness category.

Table 8: Statistical significance of social network productivity in the taxonomy

\begin{tabular}{|c|c|c|c|c|c|c|c|c|c|}
\hline & A1 & A2 & A3 & B1 & B2 & B3 & C1 & $\mathrm{C} 2$ & C3 \\
\hline A1 & 1 & 0.1389 & 0.2846 & 0.3271 & 0.1471 & 0.1585 & 0.2801 & 0.3576 & 0.2005 \\
\hline A2 & & 1 & 0.1285 & 0.5755 & 0.6384 & 0.8808 & 0.4404 & 0.5755 & 0.0037 \\
\hline A3 & & & 1 & 0.1707 & 0.1499 & 0.1389 & 0.9283 & 0.177 & 0.4777 \\
\hline B1 & & & & 1 & 0.8026 & 0.6672 & 0.1802 & 0.9761 & 0.016 \\
\hline B2 & & & & & 1 & 0.7642 & 0.1585 & 0.7949 & 0.0007 \\
\hline B3 & & & & & & 1 & 0.1471 & 0.6599 & 0.00336 \\
\hline C1 & & & & & & & 1 & 0.1835 & 0.4473 \\
\hline C2 & & & & & & & & 1 & 0.0226 \\
\hline C3 & & & & & & & & & 1 \\
\hline
\end{tabular}

\section{Discussion}

The majority of cases were found to have both average social capital and average innovativeness ( $\mathrm{N}=609,44.7 \%$ ). In order for those companies to better take advantage of SNS use, this study shows that they should focus on improving social capital and innovativeness together, since the group higher in both was found to display higher social network productivity $(\mathrm{R}=0.796, \mathrm{p}<001)$.

The use of SNS, by nature, can foster productive connections in the workplace. As hypothesized, improvements in those business connections were found to translate into an improvement in knowledge performance (social network productivity). But some companies are better positioned than others to reap this benefit, and this analysis shows that companies' levels of innovativeness and social capital affect how much they can gain from a given amount of improvement in interconnectedness.

It is therefore essential for practitioners to consider how to increase their levels of social capital and innovativeness. This study focuses here on organizational culture, defined as "the shared rules governing cognitive and affective aspects of membership in an organization, and the means whereby they are shaped and expressed" (Kunda, 1992, p. 8), as a driver of both social capital and innovativeness.

Schein (2004, p. 17) considers the culture of a group to be "a pattern of shared basic assumptions" about external adaptation and internal integration. He goes on to assert that the shared assumptions about external adaptation issues include mission and strategy, goals, means, measurements, and corrections, and that the shared assumptions about internal integration issues consist of common language and conceptual categories, group boundaries, power and status, norms of intimacy, friendship, and love, allocating rewards and punishments, and explaining the unexplainable. Looking at Schein's definition of organizational culture, social capital, which consists of interaction ties, shared vision, and 
trust and trustworthiness (Tsai and Ghoshal, 1998), is therefore directly affected by those shared assumptions about external adaptation and internal integration issues.

First, interaction ties are supported by a common language and conceptual categories which help members communicate and understand each other, and by group boundaries which define inclusion and exclusion criteria. Second, a shared vision originates from the mission and strategy which deal with the group's core mission and primary tasks. Third, trust and trustworthiness derive from power and status, norms of intimacy, friendship, and love, and allocating rewards and punishments. Power and status distribute the pecking order and help manage feelings of anxiety and aggression, while norms of intimacy, friendship, and love are concerned with the rules of peer relationships, and the allocation of rewards and punishments supports reaching a consensus.

Innovativeness itself is strongly linked to the firm's mission and strategy, and more particularly to their translation into goals, means, measurements, and corrections. The means show how goals will be reached, measurements address how goal accomplishments will be assessed, and corrections focus on the appropriate remedial and repair strategies.

Cultures basically spring and diffuse from the beliefs, values, and assumptions of founders and leaders of organizations. With renewed success, the leader's assumptions become shared and create the ground for the organization's culture whose assumptions will then be taught to newcomers. The primary mechanisms responsible for embedding specific assumptions into the group's culture largely rest on what leaders pay attention to, how they react in critical situations, how they allocate resources, rewards and status, and how they recruit, select, promote, and excommunicate. These primary mechanisms are then supported by secondary articulation and reinforcement mechanisms ingrained in the firm's organizational structure, systems and procedures, rituals, design of physical space, and shared internal success and failure stories (Schein, 2004).

For an organization to foster innovativeness for instance, innovativeness has to be found in these primary and secondary mechanisms. However, the degree of innovativeness is relative and depends on the firm's competitive position, mission, and strategy. In general, more innovative companies are more susceptible to learn from people in the organization by leveraging the knowledge of organizational members. These organizations are better capable of taking advantage of personal connections or networks which could then translate into better knowledge performance.

\section{Conclusion}

SNS were found to mildly improve efficiency in accessing knowledge or in increasing the number of business contacts. Furthermore, this study reveals that in using intranet-based SNS, companies with both higher social capital and innovativeness displayed higher social network productivity defined as the relationship between interconnectedness and knowledge performance whereby an increase in the number of business contacts may result in a shortened and less costly retrieval of work-relevant knowledge. This research indicates that management should try enhancing the organization's innovativeness and social capital in order to draw the maximum benefit of using intranet-based SNS for sharing knowledge. 
Fostering social capital and innovativeness rests largely on the firm's organizational culture which guides and constrains the expected and accepted behavior of organizational members. Because established organizational cultures tend to have inertia and are difficult to change, leaders and managers must learn how to manage and draw on the culture of their organization to carry out their mission and strategy; if they do not become conscious of the cultures in which they are embedded, those cultures will manage them.

This research, which used an existing dataset, has some limitations that should be addressed in further research: the use of SNS was treated implicitly and should therefore be measured independently and data on the respondents' organizations would be useful to reveal organizational clusters based on the constructs investigated. It is also important to note that the data used in this research provides a snapshot rather than a dynamic perspective of the influence of social capital and innovativeness on social network productivity. As a result, further research is needed to assess strategic positioning options in order to maximize social network productivity.

\section{References}

Adler, P.S., Kwon, S. (2002). Social capital: Prospects for a new concept, Academy of Management Review, 27 (1), pp. 17-40.

Ahn, J., Lee, D., Lee, S. (2006). Balancing business performance and knowledge performance of new product development: Lessons from ITS Industry, Long Range Planning, 39 (5), pp. 525-542.

Alavi, M., Leidner, D.E. (2001). Review: Knowledge management and knowledge management systems: Conceptual foundations and research issues, MIS Quarterly, 25 (1), pp. 107-136.

Alavi, M., Leidner, D.E. (1999). Knowledge management systems: Issues, challenges and benefits, Communications of the AIS, 1 (7), pp. 1-37.

Argote, L., Ingram, P. (2000). Knowledge transfer: A basis for competitive advantage in firms, Organizational Behavior and Human Decision Processes, 82 (1). pp. 150-169.

Barney, J.B. (1991). Firm resources and sustained competitive advantage, Journal of Management, 17, pp. 99-120.

Baron, R., Kenny, D. (1986). The moderator-mediator variable distinction in social psychological research: Conceptual, strategic, and statistical considerations, Journal of Personality and Social Psychology, 51 (6), pp. 1173-1182.

Berkowitz, S.D. (1982). An introduction to structural analysis: The network approach to social research, Butterworth, Toronto.

Bigoness, W.J., Perreault, W.D. (1981). A conceptual paradigm and approach for the study of innovators, Academy of Management Journal, 24 (1), pp. 68-82.

Booz, Allen, \& Hamilton (1982). New product management for the 1980s, Booz-Allen \& Hamilton, New York, NY.

Boyd, D.M., Ellison, N.B. (2007). Social network sites: Definition, history, and scholarship, Journal of Computer-Mediated Communication, 13 (1), article 11.

Burt, R. (1992). Structural holes: The social structure of competition, Harvard University Press, 
Cambridge, MA.

Choi, S.Y., Kang, Y.S., Lee, H. (2008). The effects of socio-technical enablers on knowledge sharing: An exploratory examination, Journal of Information Science, 34 (5), pp. 742-754.

Coleman, J.S. (1988). Social capital in the creation of human capital, American Journal of Sociology, 94 (Supplement), pp. S95-S120.

Coleman. J.S. (1990). Foundations of social theory, Belknap Press of Harvard University Press, Cambridge, MA.

Dalkir, K. (2005). Knowledge management in theory and practice, Elsevier Butterworth-Heinemann, Burlington, MA.

Davenport, T., Prusak, L. (1998). Working knowledge, Harvard Business School Press, Boston, MA.

Ellison, N.B., Steinfield, C., Lampe, C. (2007). The benefits of Facebook "Friends:" Social capital and college students' use of online social network sites, Journal of Computer-Mediated Communication, 12, pp. 1143-1168.

Falk, R.F., Miller, N.B. (1992). A Primer for Soft Modeling, University of Akron Press, Akron, $\mathrm{OH}$.

Field, A. (2005). Discovering Statistics Using SPSS, Sage, London.

Fisher, R.A. (1915). Frequency distribution of the values of the correlation coefficient in samples of an indefinitely large population, Biometrika, 10 (4), pp. 507-521.

Grant, R. (1996). Prospering in dynamically-competitive environment: Organizational capability as knowledge integration, Organization Science, 7, pp. 375-387.

Hariharan, A. (2002). Knowledge management: A strategic tool, Journal of Knowledge Management Practice, 3, article 46.

Holsapple, C.W., Joshi, K.D. (2000). An investigation of factors that influence the management of knowledge in organizations, Journal of Strategic Information Systems, 9, pp. 235-261.

Jiang, X., Li, Y. (2009). An empirical investigation of knowledge management and innovative performance: The case of alliances, Research Policy, 38 (2), pp. 358-368.

Jordan, G., Segelod, E. (2006). Software innovativeness: Outcomes on project performance, knowledge enhancement, and external linkages, $R$ and D Management, 36 (2), pp. 127-142.

Knight, L.V., Steinbach, T.A., Settimi, R. (2005). An exploratory analysis of Intranet benefits, Proceedings of the 2005 Informing Science and IT Education Joint Conference, Flagstaff, Arizona, USA, June 16-19, 2005, pp. 109-123.

Kodama, M. (2000). Transforming an old economy company through strategic communities, Long Range Planning, 35, 349-365.

Kodama, M. (2005). Knowledge creation through networked strategic communities: Case studies on new product development in Japanese companies, Long Range Planning, 38(1), 27-49.

Kogut, B., Zander, U. (1996). What firms do? Coordination, identity, and learning, Organization Science, 7 (5), pp. 502-518.

Kunda, G. (1992). Engineering Culture: Control and Commitment in a High-Tech Corporation, 
Temple University Press, Philadelphia, PA.

Magnier-Watanabe, R., Senoo, D. (2008). Organizational characteristics as prescriptive factors of knowledge management initiatives, Journal of Knowledge Management, 12(1), pp. 21-36.

McAfee, A.P. (2006). Enterprise 2.0: The dawn of emergent collaboration, MIT Sloan Management Review, 47 (3).

Mendelson, H. (2000). Organizational architecture and success in the information technology industry, Management Science, 46 (4), pp. 513-529.

Mendelson, H., Pillai, R.R. (1998). Clockspeed and informational response: Evidence from the IT industry, Information Systems Research, 9 (4), pp. 415-433.

Merono-Cerdan, A.L., Soto-Acosta, P., Lopez-Nicolas, C. (2008). Analyzing collaborative technologies' effect on performance through Intranet use orientations, Journal of Enterprise Information Management, 21 (1), pp. 39-51.

MIC (2008). Communication usage trend survey, Japanese Ministry of Internal Affairs and Communications (MIC), April, http://www.johotsusintokei.soumu.go.jp/tsusin_riyou/data/eng tsusin_riyou02_2007.pdf).

Minetaki, K., Yoshida, M. (2006). Service Innovation Generated by Innovation in ICT Blogs/SNSs and Innovation - The Effect of Blogs/SNSs as seen from a Survey of Employees, Fujitsu Research Institute, Research Paper No. 282.

Nahapiet, J., Ghoshal, S. (1998) Social capital, intellectual capital, and the organizational advantage, Academy of Management Review, 23 (2), pp. 242-266.

Nonaka, I., Toyama, R., Konno, N. (2000). SECI, 'ba' and leadership: A unified model of dynamic knowledge creation, Long Range Planning, 33 (1), pp. 5-34.

Padula, G. (2008). Enhancing the innovation performance of firms by balancing cohesiveness and bridging ties, Long Range Planning, 41 (4), pp. 395-419.

Putnam, R.D. (2004). Commentary: “Health by association”: Some comments, International Journal of Epidemiology, 33, pp. 667-671.

Putnam, R.D., Leonardi, R., Nanetti, R. (1993). Making democracy work: Civic traditions in modern Italy, Princeton University Press, Princeton, NJ.

Putnam, R.D. (1995). Tuning in, tuning out: The strange disappearance of social capital in America, Political Science and Politics, 28 (4), pp. 664-683.

Ravasi, D., Verona, G. (2001). Organizing the process of knowledge integration: The benefits of structural ambiguity, Scandinavian Journal of Management, 11, pp. 41-66.

Rogers, E.M. (1962). Diffusion of innovations, The Free Press, New York, NY.

Ruggles, R. (1998). The State of the notion: Knowledge management in practice, California Management Review, 40 (3), pp. 80-89.

Schein, E.H. (2004) Organizational Culture and Leadership, Jossey-Bass, San Francisco, CA.

Sherif, K., Hoffman, J., Thomas, B. (2006). Can technology build organizational social capital? The case of a global IT consulting firm, Information and Management, 43 (7), pp. 795-804.

Shin, M., Holden, T., Schmidt, R.A. (2001). From knowledge theory to management practice: 
Toward an integrated approach, Information Processing and Management, 37, pp. 335-355.

Simon, H.A. (1997). Administrative behavior (4th Ed.), The Free Press, New York, NY.

Spender, J.C. (1996). Making knowledge the basis of a dynamic theory of the firm, Strategic Management Journal, 17, pp. 45-62.

Spender, J.C., Grant, R.M. (1996). Knowledge and the firm: overview, Strategic Management Journal, 17, pp. 5-9.

Subramaniam, M., Youndt, M.A. (2005). The influence of intellectual capital on the types of innovative capabilities, Academy of Management Journal, 48, pp. 450-463.

Teece, D.J., Pisano, G., Shuen, A. (1997). Dynamic capabilities and strategic management, Strategic Management Journal, 18 (7), pp. 509-533.

Tsai, W. (2001). Knowledge transfer in intra-organizational networks: Effects of network position and absorptive capacity on business unit innovation and performance, Academy of Management Journal, 44 (5), pp. 996-1004.

Tsai, W., Ghoshal, S. (1998). Social capital and value creation: The role of intra-firm networks, Academy of Management Journal, 41, pp. 464-476.

Uzzi, B. (1996). The sources and consequences of embeddedness for the economic performance of organizations: The network effect, American Sociological Review, 61 (4), pp. 674-98.

Van Trijp, H.C.M., Van Kleef, E. (2008). Newness, value and new product performance, Trends in Food Science and Technology, 19 (11), pp. 562-573.

Von Krogh, G., Roos, J. (1995). Organizational epistemology, Macmillan and St. Martin’s Press, New York, NY.

Wallace, A.F.C. (1961). Culture and personality, Random House, New York, NY.

Weick, K.E. (1979). The social psychology of organizing (2nd Ed.), McGraw-Hill, New York, NY. 


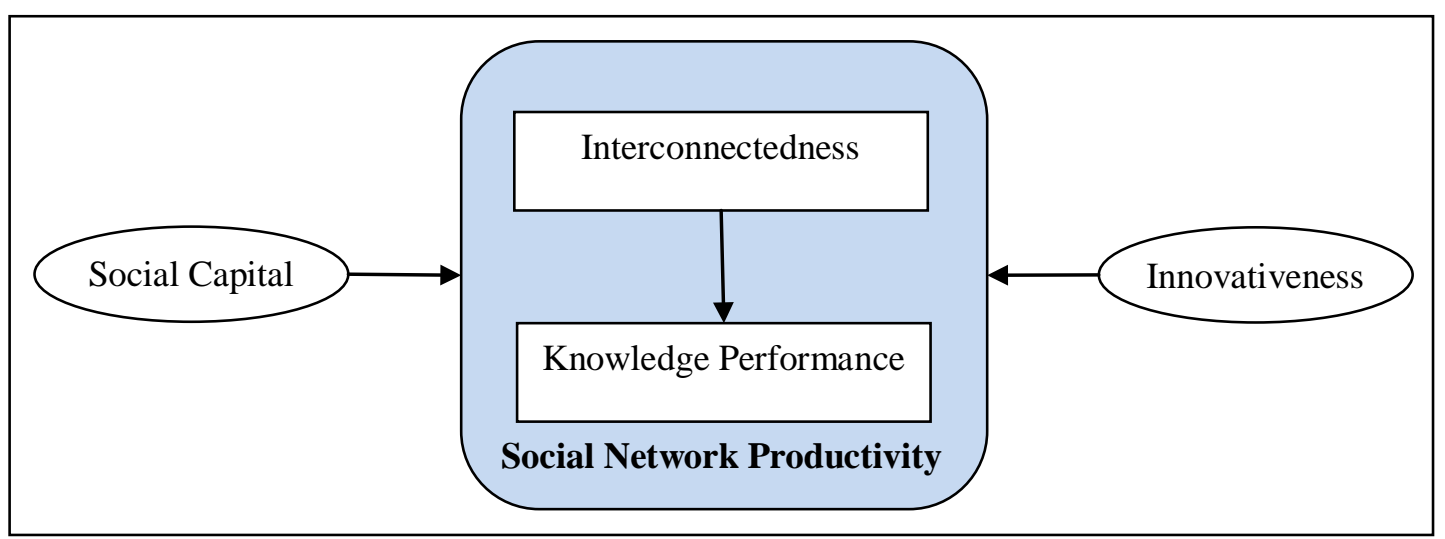

Figure 1: The moderating effect of social capital and innovativeness on social network productivity
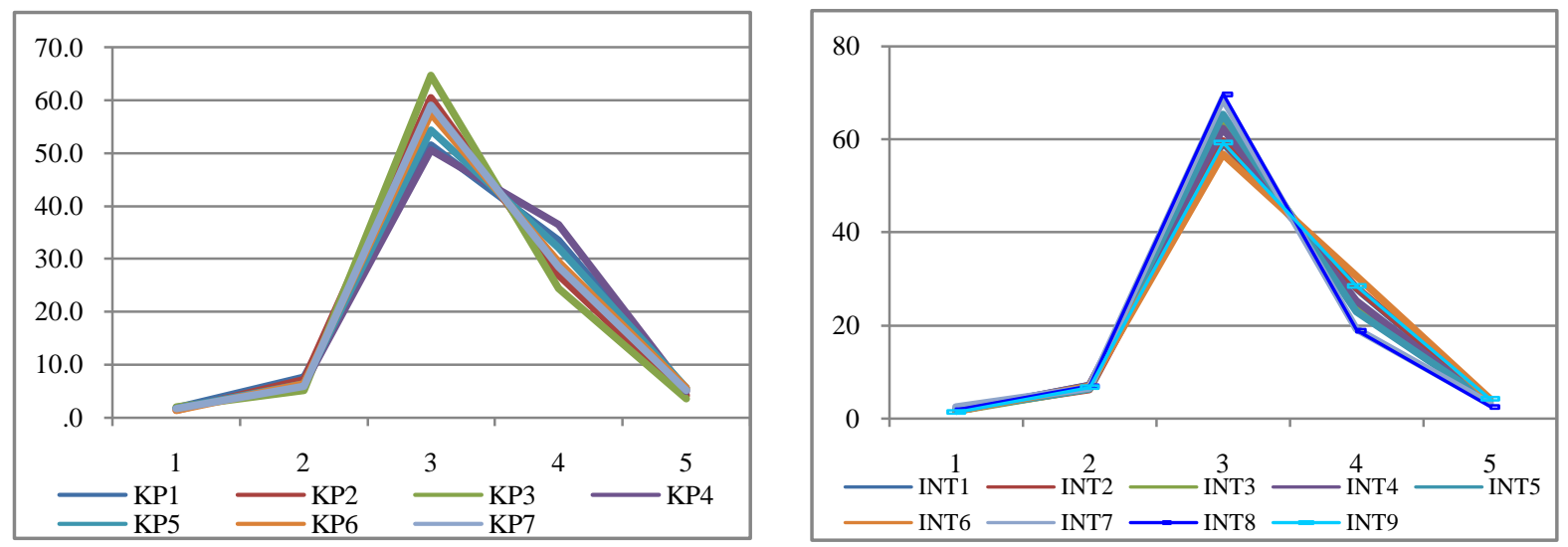

Figure 2: Percentage distribution of the respondent's answers on the influence of SNS on knowledge performance and on interconnectedness

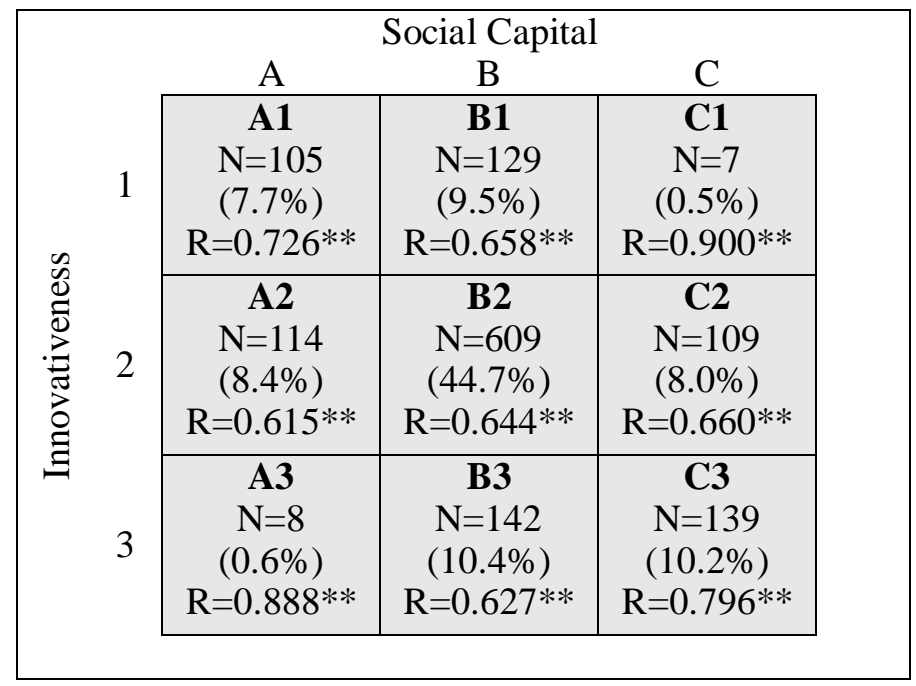

Figure 3: Social network productivity relative to levels of social capital and innovativeness 